\title{
Giant Pseudoaneurysm of a Splanchnic Artery: A Case Report
}

\section{Nwafor IA*, Eze JC, Ezemba N, Ngene $\mathrm{Cl}$ and Akpan AF}

National cardiothoracic Center of Excellence, University of Nigeria Teaching Hospital, Ituku/Ozalla, Enugu, Nigeria

Keywords: Pseudoaneurysm; Splanchnic artery; Thrombi; Mesentery; Crossclamp; Heparin

\section{Introduction}

A true aneurysm is defined as an enlargement of an artery resulting in a diameter more than 1.5 times the anatomic size [1]. It can be fusiform when it covers the entire perimeter of the vessel, or saccular when it bulges on one side of the artery. The pseudoaneurysm is a pulsating encapsulated haematoma in communication with the lumen of the ruptured vessel, which affects the the intima and the media and which is stopped from developing by the adventitia and the surrounding connective tissue [2]. Geographically, aneurysm can be broadly divided into intracranial and extracranial types. While the neurosurgeon manages the intracranial types, the vascular surgeon manages the extracranial types [3]. Vascular surgeons also do divide the extracranial types into central (abdominal-aorto-iliac, thoracic including ascending, transverse aortic arch and descending), peripheral (extremities) and visceral (splanchnic arteries) [4]. Splanchnic artery aneurysm includes the coeliac, superior mesenteric, inferior mesenteric arteries including their branches. Of all intra-abdominal aneurysms, only around $5 \%$ are due to the splanchnic arteries, which could be either true or pseudo [5]. The prevalence has been estimated at $0.1-0.2 \%$ [6].

\section{Case Report}

A 53-year old motor mechanic man presented to us 3 months prior with 8- year history of epigastric pain and progressive abdominal swelling. The pain was insidious in onset, moderate in intensity, variable in character, ranging from dull, sharp to burning. Pain was referred to the back including spine. It was relieved by food and analgesics. It was not periodic and no associated nausea or vomiting. Few months later abdominal swelling developed around the epigastric area. It gradually increased in size. There was however no change in bowel habit and no easy satiety. There was no history of cough or contact with any person with chronic cough. There was no history of loss of weight or night sweat. There was no history of any swelling in any other part of the body. There was no history of fever nor jaundice, but there was feeling of pulsation around the mass. He consequently presented to a private hospital a year prior to our review. There, he had laparotomy because, the surgeon thought it was a mesenteric cyst with transmitted pulse. The surgeon abandoned the procedure when he aspirated bright red non clotting blood. He requested for abdominal ultrasound which revealed abdominal aortic aneurysm. This necessitated referring the patient to our center.

For the epigastric pain, he had been treated for unproven peptic ulcer disease a year prior to full blown symptoms with gestids and other anti-peptic ulcer drugs. He was not a known hypertensive or diabetic. Family and social history was not contributory.

Examination revealed a preserved middle age asthenic man in no obvious distress. He was afebrile to touch, anicteric, not pale, not dehydrated, acyanosed and with no digital clubbing and no peripheral lymphadenopathy nor pedal oedema. Abdomen revealed a midline surgical scar, asymmetrically distended abdomen around the epigastric region. The abdomen moved with respiratory excursion. A palpable mass was felt, which was non tender, firm in consistency, oval shaped and measured 16 by $12 \mathrm{~cm}$. The inferior limit was delineable unlike the superior limit. The mass was mobile in transverse direction and had positive thrill and bruit (Figure 1).

Other systemic examinations were not contributory. Our working diagnosis was at variance with the abdominal ultrasound based on the mobility of the mass and the presence of a bruit. Our diagnosis was that of a vascular mass with either arteriovenous or arteriovisceral fistula. A computerized scan angiography was then requested and it showed a confluent pseudoaneurysm involving a branch of hepatic and a branch of splenic arteries, see (Figure 2). His haematological and biochemical parameters requested were within normal range. He was the rescheduled for operation with four units of blood.

A longitudinal incision combined with left transverse incision laparotomy was done. The findings were: a pulsatile mass with a thrill, 16 by $20 \mathrm{~cm}$ in size. Stomach and pancreas were firmly adherent to the mass, thick walled $(2.5 \mathrm{~cm})$ (Figure 3); the splenic and hepatic artery branches were feeding the mass. About a litre of blood including darkred thrombi, $10 \times 7 \mathrm{~cm}$ was contained in the sac.

A proximal control of the abdominal aorta was obtained with aortic cross clamp above the mass after infusion of 5 international units of unfractionated heparin. Distal control was obtained by identifying the common iliac arteries and snaring them with tapes. The aneurysmal sac was then opened and the above findings noted. The orifices of the

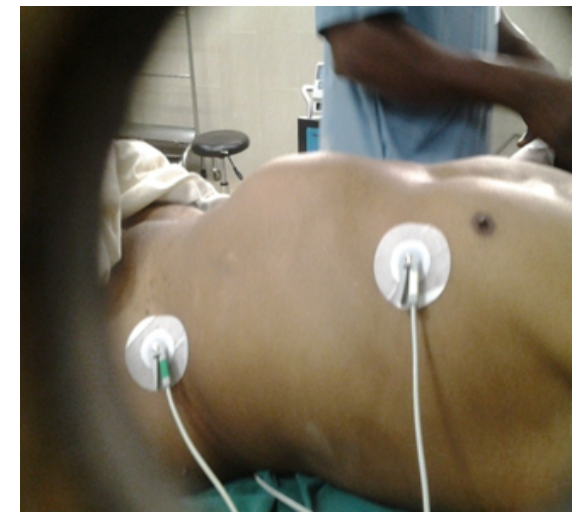

Figure 1: Abdomen distension around epigastric region.

*Corresponding author: Nwafor IA, National Cardiothoracic Center Of Excellence UNTH, Enugu, Nigeria, Tel: +2348037784860; E-mail: igbochinanya2@yahoo.com

Received May 28, 2015; Accepted June 25, 2015; Published June 27, 2015

Citation: Nwafor IA, Eze JC, Ezemba N, Ngene Cl, Akpan AF (2015) Giant Pseudoaneurysm of a Splanchnic Artery: A Case Report. J Vasc Med Surg 3: 208. doi:10.4172/2329-6925.1000208

Copyright: @ 2015 Nwafor IA, et al. This is an open-access article distributed unde the terms of the Creative Commons Attribution License, which permits unrestricted use, distribution, and reproduction in any medium, provided the original author and source are credited. 
Citation: Nwafor IA, Eze JC, Ezemba N, Ngene Cl, Akpan AF (2015) Giant Pseudoaneurysm of a Splanchnic Artery: A Case Report. J Vasc Med Surg 3: 208. doi:10.4172/2329-6925.1000208

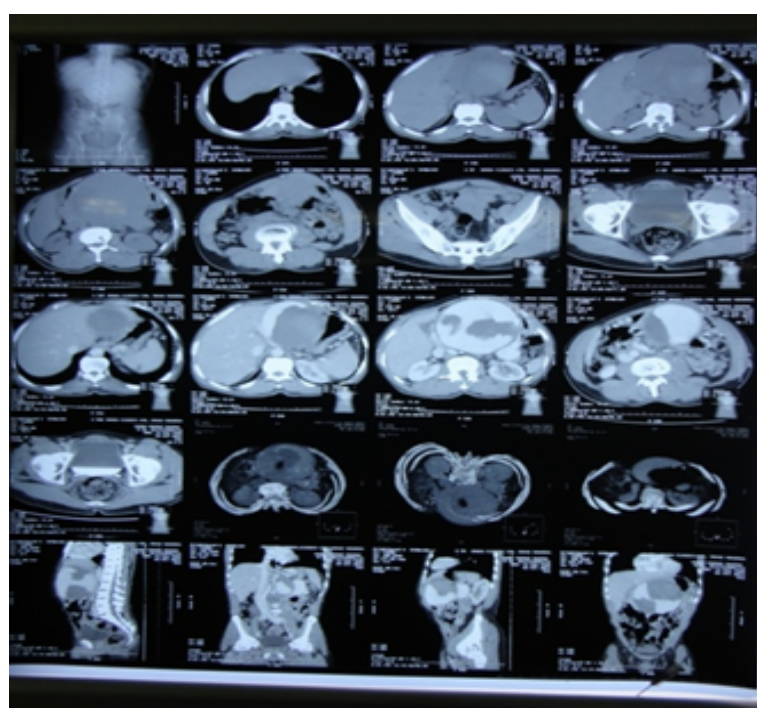

Figure 2: Ct scan angiography.

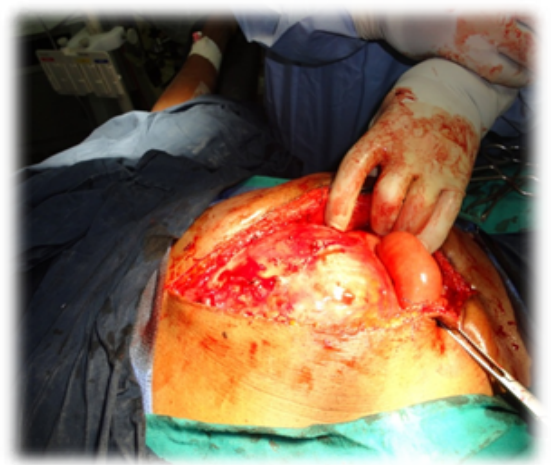

Figure 3: Longitudinal midline laparatomy, displaying the pseudoaneurysm.

hepatic and splenic artery branches were identified and suture ligated; (Figures 4-8). The sac was carefully trimmed down and obliterated using absorbable suture, vicryl $2 / 0$. The resected specimen was sent for histology. Abdomen was closed with indwelling catheter, $28 \mathrm{Fr}$. He had 3 units of blood intra-operatively and a unit of blood postoperatively. He made uneventful recovery and was discharged home on the $8^{\text {th }}$ postoperative day and had been followed up severally at the surgical outpatient with no complication. Histology of the specimen (pieces of the sac): inflammatory due to chronic pancreatitis.

\section{Discussion}

Splanchnic aneurysms are rare conditions. No case documentation has been noted in Nigeria and West African subregion, hence this case report. It has unpredictable evolution, often leading to sudden death syndrome. Tracing splanchnic artery aneurysm is very important because of high death rate (25-75\%), backup massive haemorrhage, embolic and/or organ ischemic complications. Usually, splanchnic aneurysms are asymptomatic or have nonspecific symptomns [7]. They can manifest dramatically when intraperitoneal haemorrhage arrives or a bit more 'gentle' in cases of sporadic digestive heamorrhage or rupture in the portal vascular system. In this case, portal hypertension emerges with accompanying visceral bleeding [8].
The most common location is at the level of splenic artery (58\%), hepatic artery (20\%), superior mesenteric artery (8\%), including gastroduodenal and pancreaticoduodenal arteries and inferior mesenteric artery (1\%) as well as the celiac aartery(4\%) [7-9]. It may be multiple [10]. Our index patient had pseudoaneurysm involving a

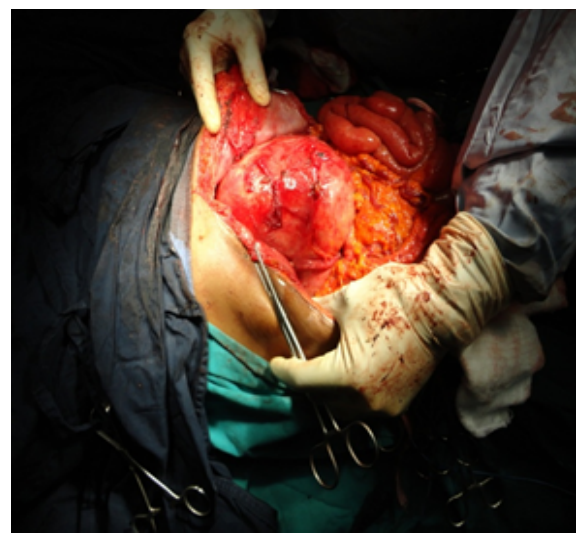

Figure 4: Midline longitudinal and left transverse laparatomy displaying the pseudoaneurysm.

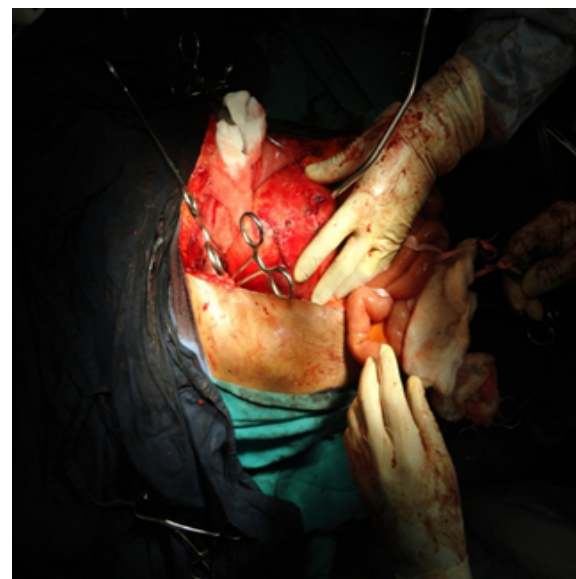

Figure 5: Proximal aortic crossclamp above the pseudoaneurysm.

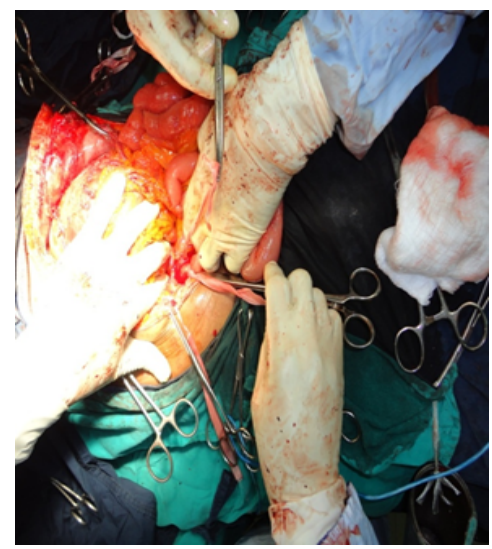

Figure 6: Common iliac arteries identified and snared with tapes. 


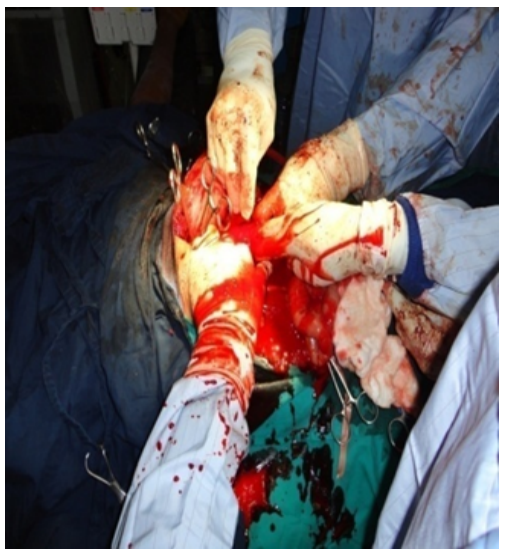

Figure 7: Aneurismal sac opened and blood and thrombi being removed.

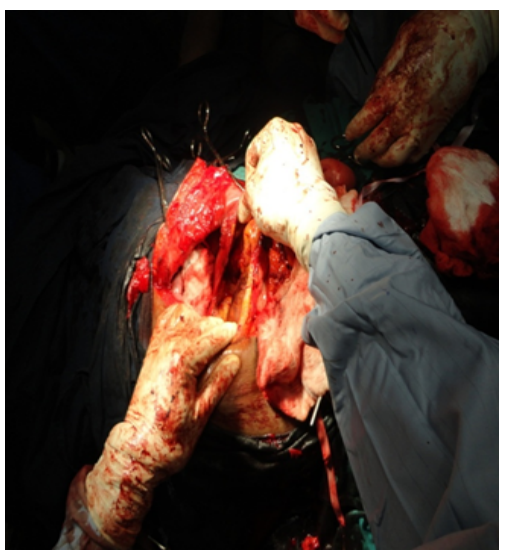

Figure 8: The aneurysmal sac being displayed.

branch of hepatic and a branch of splenic arteries which coalesced to form a common cavity.

Splenic artery aneurysm is $72 \%$ true and $28 \%$ pseudo. The rupture rate is $25-40 \%[9,10]$ and the risk is three times higher in pregnant women, $[1,6,11,12]$. The risk factors for the aneurysm are portal hypertension, fibromuscular dysplasia, panfcreatitis, more often causing pseudoaneurysm, as was seen in our index patient; arteriosclerosis, abdominal trauma, inflammatory diseases, septic emboli or congenital diseases like Ehlers Danlos' syndrome and Marfan's syndrome [1,4]. The presentation is generally nonspecific and diagnosis may be incidental or through abdominal X-ray (calcified) [6], ultrasound or through computerized tomography scan including angiography and magnetic resonance angiography. Our index patient was symptomatic, wrongly diagnosed as abdominal aortic aneurysm but detailed clinical evaluation with CTA, accurate diagnosis was made. The treatment for a true aneurysm involving the proximal and mid splenic artery is surgical resection without reconstruction. However, involvement of the distal part or the hilum requires resection with splenectomy [13] and if it occurs in a child, patient should be given pneumococcal vaccine.

Hepatic artery aneurysm occurs more in men than women. Aetiologically, 50\% of cases are iatrogenic (interventional procedures on the biliary tree) or abdominal trauma [14]. It may be extrahepatic or intrahepatic. It has the same risk factor like that of the splenic artery. Rupture rate is $44-80 \%$ [15] with a death rate of $21-35 \%$ [1,16].
Coeliac artery has the same risk factors as mentioned above. Rate of rupture is low. Treatment when it occurs is ligation with a bypass or percutaneous embolization [17].

Superior mesenteric artery aneurysm may be asymptomatic or may cause diffuse abdominal pain or digestive haemorrhage. Septic embolism is the cause in $33 \%$ of cases [18]. Treatment is surgical resection or embolisation. Pseudoaneurysm of pancreaticoduodenal arotery may be due to pancreaticodouodenectomy [19]. Intense upper abdominal pain may precede the rupture. Mortality rate is on the high side, approaching $50 \%$.

\section{Conclusion}

Due to the rarity and nonspecific presentation of this splanchnic artery in addition that it can cause sudden death syndrome, a high index of suscipision should be the watchword in any patient presenting with abdominal symptoms. Such patient should be made to undergo at least an abdominal ultrasound. Moreso, due to the fact that some, especially hepatic artery aneurysm does present at late age, i.e., $5^{\text {th }}$ ot $6^{\text {th }}$ decade of life, routine yearly abdominal ultrasound should be used as screening tool at least from the age of 45 years. Pregnant women who are also prone to this problem should have their pregnancy properly supervised. Treatment should either be elective (asymptomatic/ expanding) and emergent when ruptured.

\section{References}

1. Johnston KW, Rutherford RB, Tilson MD, Shah DM, Hollier L, et al. (1991) Suggested standards for reporting on arterial aneurysms. Subcommittee on Reporting Standards for Arterial Aneurysms, Ad Hoc Committee on Reporting Standards, Society for Vascular Surgery and North American Chapter, International Society for Cardiovascular Surgery. J Vasc Surg 13: 452-458.

2. Pulli R, Dorigo W, Troisi N, Pratesi G, Innocenti AA, et al. (2008) Surgica treatment of visceral artery aneurysms: A 25-year experience. J Vasc Surg 48: 334-342.

3. Eze JC, Ezemba N, Adamu Y (2010) A study of extracranial aneurysms at UNTH in Enugu, Nigeria. Niger J Clin Pract 13: 272-275.

4. Nwafor IA, Eze JC, Ezemba N, Anyanwu CH (2012) The challenges facing the management of arterial aneurysm in UNTH, Enugu. Niger J Med 21: 438-440.

5. Meng WCS, Chan WY, Li AKC (1995) Splanchnic Artery Aneurysm. HKMJ 1 173-177.

6. Bedford PD, Lodge B (1960) Aneurysm of the splenic artery. Gut 1: 312-320.

7. Pasha SF, Gloviczki P, Stanson AW, Kamath PS (2007) Splanchnic artery aneurysms. Mayo Clin Proc 82: 472-479.

8. Pasternak BM, Cohen $\mathrm{H}$ (1978) Arteriovenous fistula and forward hypertension in the portal circulation. Angiology 29: 367-373.

9. Abbas MA, Stone WM, Fowl RJ, Gloviczki P, Oldenburg WA, et al. (2002) Splenic artery aneurysms: two decades experience at Mayo clinic. Ann Vasc Surg 16: 442-449.

10. Busutil RW, Brim BJ () The diagnosis and management of visceral artery aneurysm and pseudoaneurysm. Cardiovasc Intervent Radiol 17: 179-184.

11. Holdsworth RJ, Gunn A (1992) Ruptured splenic artery aneurysm in pregnancy. A review. Br J Obstet Gynaecol 99: 595-597.

12. Hallett JW Jr (1995) Splenic artery aneurysms. Semin Vasc Surg 8: 321-326.

13. Hashizume M, Ohta M, Ueno K, Okadome K, Sugimachi K (1993) Laparoscopic ligation of splenic artery aneurysm. Surgery 113: 352-354.

14. Shanley CJ, Shah NL, Messina LM (1996) Common splanchnic artery aneurysms: splenic, hepatic, and celiac. Ann Vasc Surg 10: 315-322.

15. Stanley JC (1987) Abdominal visceral aneutrysm. In: Harmovici H(ed) Vascular emergencies. New York: Appleton Century Crofts 387-396.

16. Carr SC, Pearce WH, Vogelzang RL, McCarthy WJ, Nemcek AA Jr, et al. (1996) Current management of visceral artery aneurysms. Surgery 120: 627-633. 
Citation: Nwafor IA, Eze JC, Ezemba N, Ngene Cl, Akpan AF (2015) Giant Pseudoaneurysm of a Splanchnic Artery: A Case Report. J Vasc Med Surg 3: 208. doi:10.4172/2329-6925.1000208

Page 4 of 4

17. Stone WM, Abbas MA, Gloviczki P, Fowl RJ, Cherry KJ (2002) Celiac arterial aneurysms: a critical reappraisal of a rare entity. Arch Surg 137: 670-674.

18. Cormier F, Ferry J, Artru B, Wechsler B, Cormier JM (1992) Dissecting aneurysms of the main trunk of the superior mesenteric artery. $\mathrm{J}$ Vasc Surg 15: $424-430$

19. Granke K, Hollier LH, Bowen JC (1990) Pancreaticoduodenal artery aneurysms: changing patterns. South Med J 83: 918-921. 